\title{
Patrimoine géologique
}

\section{Inventaire national}

\author{
par \\ Patrick De Wever, \\ Grégoire Egoroff, \\ Annie Cornée, \\ Pierrick Graviou, \\ Jacques Avoine \\ et Laura Baillet
}

pour la Commission de validation nationale de l'inventaire du patrimoine géologique 
Photos de couverture : Toutes les photos de cette couverture et les crédits associés sont présents dans l'ouvrage Composition et mise en pages : Patrick Leleux PAO

Imprimé en France

ISBN : 978-2-7598-2294-2

Tous droits de traduction, d'adaptation et de reproduction par tous procédés, réservés pour tous pays. La loi du 11 mars 1957 n'autorisant, aux termes des alinéas 2 et 3 de l'article 41, d'une part, que les " copies ou reproductions strictement réservées à l'usage privé du copiste et non destinés à une utilisation collective ", et d'autre part, que les analyses et les courtes citations dans un but d'exemple et d'illustration, " toute représentation intégrale, ou partielle, faite sans le consentement de l'auteur ou de ses ayants droit ou ayants cause est illicite " (alinéa 1 er de l'article 40). Cette représentation ou reproduction, par quelque procédé que ce soit, constituerait donc une contrefaçon sanctionnée par les articles 425 et suivants du code pénal.

(C) EDP Sciences, 2018 